\title{
Efficacy of Liquorice and Propolis Extract Used as Cavity Cleaning Agents against Streptococcus mutans in Deciduous Molars Using Confocal Microscopy: An In Vitro Study
}

\author{
Eva Godbole ${ }^{1}$, Sanjeev Tyagi ${ }^{2}$, Parimala Kulkarni ${ }^{3}$, Shilpy Singla ${ }^{4}$, Shikha Mali ${ }^{5}$, Surabhi Helge ${ }^{6}$
}

\begin{abstract}
Background/introduction: Cavity disinfection before restoration aids in reducing the number of residual bacteria, thus, decreasing the rate of secondary caries. Propolis, at low concentrations, inhibits the growth of cariogenic bacteria. Liquorice roots are known to have antimicrobial, anti-inflammatory, and antioxidant properties.

Aim and objectives: Evaluation and comparison of antimicrobial efficacy of liquorice and propolis extract gels used as cavity cleaning agents against Streptococcus mutans in deciduous molars by confocal laser scanning microscopy (in vitro study).

Materials and methods: Liquorice and propolis extracts were converted into gels after recording the minimum inhibition concentration. Class I cavity was prepared on 135 extracted deciduous molars and subjected to inoculation with S. mutans. Teeth were randomly divided into groups I, II, and III which were treated with gels of liquorice, propolis, and distilled water, respectively, for 60, 120, and 180 seconds each. Specimens were sectioned and stained with fluorescent dyes and observed under a confocal laser scanning microscopy (CLSM). The data obtained were statistically evaluated.

Results: The mean nonviable/viable bacterial count and the depth of penetration were found to be maximum in group I and minimum in group III. A statistically significant difference was found to be between groups I and II and groups I and III, while with groups II and III, it was nonsignificant at all 60,120, and 180 seconds. The bacterial depth penetration between groups I and II at 180 seconds was nonsignificant.

Conclusion and clinical significance: Though liquorice showed better antimicrobial potential as compared to propolis extract, both can be used efficiently as cavity disinfectants.

Keywords: CLSM, Liquorice, Propolis.

International Journal of Clinical Pediatric Dentistry (2019): 10.5005/jp-journals-10005-1620
\end{abstract}

\section{INTRODUCTION}

The use of cavity disinfectants before the restorative procedure is an important clinical step because bacteria adhere in the smear layer or in the dentinal tubules and can potentially multiply resulting in the development of secondary caries under restoration. ${ }^{1}$

The constant increase in antibiotic-resistant strains and the side effects caused by synthetic drugs have prompted researchers to look for herbal alternatives. Recently, there has been a growing trend to seek natural remedies as a part of dental treatment and this approach may be termed phytotherapeutics or ethnopharmacology. ${ }^{2}$ The major advantages of using natural alternatives are easy availability, cost effectiveness, increased shelf life, low toxicity, and lack of microbial resistance reported so far.

Propolis is a resin widely used in folk medicine for centuries. Propolis is a resinous material that honeybees collect from various plant species and mix with wax and other substances to fill their hives cracks and crevices, and it has a complex chemical composition. ${ }^{2,3}$ Scientific research has revealed its antioxidant, antibacterial, anti-fungal, antiviral, anti-inflammatory, antitumor, and immunomodulating properties. ${ }^{2}$

Pharmacologically active constituents in propolis are flavonoids, phenolic, and aromatics. ${ }^{4}$ It exhibits various biologic activities, including antimicrobial, anti-inflammatory, antioxidant, anesthetic, and cytotoxic properties. The anti-inflammatory property of propolis is due to the presence of caffeic acid and phenethyl ester in propolis. ${ }^{4}$ There are specific compounds in propolis that can, at low concentrations, inhibit the growth of cariogenic bacteria and
${ }^{1-6}$ Department of Pediatric and Preventive Dentistry, People's College of Dental Sciences and Research Center, Bhopal, Madhya Pradesh, India Corresponding Author: Eva Godbole, Department of Pediatric and Preventive Dentistry, People's College of Dental Sciences and Research Center, Bhopal, Madhya Pradesh, India, Phone: +91 9890925648, e-mail: eva.godbole@gmail.com

How to cite this article: Godbole E, Tyagi S, et al. Efficacy of Liquorice and Propolis Extract Used as Cavity Cleaning Agents against Streptococcus mutans in Deciduous Molars Using Confocal Microscopy: An In Vitro Study. Int J Clin Pediatr Dent 2019;12(3):194-200.

Source of support: Nil

Conflict of interest: None

the activity of the glucosyltransferases (GTFs), which are associated with the pathogenesis of dental caries. ${ }^{5}$

Glycyrrhiza glabra, commonly known as liquorice, is one of the most important traditional medicinal plants and it has been used for medicinal purposes for more than 4,000 years and is also known as Mulethi or Jyeshtamadhu. Glycyrrhiza glabra L. (liquorice) belonging to family Fabaceae consists of dried roots of the plant that is native to the Mediterranean region and central and southwest Asia. Glycyrrhizin is the main constituent in liquorice responsible for its anti-inflammatory activity. ${ }^{6}$ The flavonoid content of the liquorice extract is also a strong inhibitor of oxygen consumption in bacterial cells. Liquorice has also shown a greater biocompatibility 
with fibroblasts cells compared to calcium hydroxide, which was severely toxic to the cells. ${ }^{7}$ It is the most commonly used crude drug and flavoring agent in Kampo medicines [traditional Chinese medicines modified in Japan] and is known to have antimicrobial, anti-inflammatory, and antioxidant properties. ${ }^{7}$ It has been used as an intracanal agent and a root canal irrigant in some studies. Liquorice at a concentration of $50 \%$ has an inhibitory effect on Streptococcus mutans and Enterococcus faecalis. Liquorice also shows good antimicrobial activity against Streptococcus aureus. ${ }^{8}$

CLSM has been used to evaluate bacterial viability in dentin biofilms. Fluorescent dyes are applied on the biofilm to differentiate live and dead bacteria, allowing bacteria to be distinguished according to the cytoplasmic membrane permeability. ${ }^{9}$ Furthermore, CLSM can capture a series of image scans showing changes in the viability of the bacterial cell over time, making the visualization of real-time death of microorganisms possible. ${ }^{9}$

The present study evaluated and compared the antimicrobial efficacy of liquorice and propolis extract gels used as cavity cleaning agents against $S$. mutans (MTCC 497) in deciduous molars through CLSM (ZIESS LSM 780 META GmbH, Mannheim, Germany).

\section{Materials and Methods}

\section{Source of Data}

The study was conducted at the Department of Paedodontics and Preventive Dentistry, People's College of Dental Science and Research Centre, Bhopal, Lienence Microbiology Lab, Bhopal, and Indian Institute of Science Education and Research, Bhopal, after obtaining ethical clearance from the Institutional Ethical Committee. The study details were explained and informed consent was obtained from the patient's parents before the extraction of teeth. The consent forms were prepared according to WHO Informed Parental Consent form for Research.

\section{Inclusion Criteria}

135 overretained, noncarious deciduous molars.

\section{Exclusion Criteria}

Dentinal caries, defective dentin (dentin dysplasia, dentinogenesis imperfecta, dentin hypocalcification).

The study design consisted of 135 human deciduous molars. After inoculation with S. mutans (MTCC 497), the teeth were divided randomly into three groups: group I $(n=45)$ which was treated with liquorice extract containing gel, group II $(n=45)$ with propolis extract containing gel, and group III $(n=45)$ was treated with distilled water (control). These three groups were further subdivided into three subgroups based on the duration of application of the cavity cleaning agent used for each group, respectively, i.e., 60, 120, and 180 seconds.

\section{Study Methodology}

- Preparation of extracts

- Preparation of gels

- Preparation of specimens

- Culturing procedure

- Preparation of specimens for CLSM and evaluation

\section{Preparation of Extracts}

A solvent system of $80 \%$ ethanol was used for the extraction of phytochemicals from the crude liquorice and propolis powder. Twenty-five grams of crude liquorice and propolis powder were weighed in separate containers and loaded separately inside two thimbles (middle assembly of apparatus). The thimble was loaded into the middle chamber of the Soxhlet extractor. About $80 \%$ of the ethanol was prepared and placed in a round bottom flask which was used as an extraction solvent (i.e., placed in the lower assembly of apparatus). The flask was then placed on the heating element and a thimble was placed on top of a round bottom flask. A reflux condenser was placed on top of the extractor. The temperature of the heating mantle was set at $60^{\circ} \mathrm{C}$. The extraction completed after 2 days with continuous $6-8 \mathrm{~h}$ of soxhlation. The same procedure was used for both liquorice and propolis. The extract obtained was subjected to the microbiological procedure to achieve minimal inhibitory concentration through serial dilutions. The effective concentrations of the extracts were then concentrated into gel.

\section{Procedure for Gel Preparation}

About $100 \mathrm{~mL}$ of distilled water was taken in a beaker and was placed on a magnetic stirrer with a hot plate, continuous uniform stirring was maintained throughout the procedure using a magnetic bead. About $1 \mathrm{~g}$ of carbapol was added while stirring for about 20-30 minutes until it was uniform and viscous. Then, $1 \mathrm{~mL}$ of propyl glycol and $1.5 \mathrm{~mL}$ of glycerol were added, followed by the addition of $200 \mu \mathrm{g}$ of methyl paraben. After uniform mixing of all ingredients of gel, $10 \mathrm{~mL}$ of prepared concentrations of an extract of propolis/ liquorice were added. In the final step, a few drops of triethanolamine solution added into the whole mixture while stirring continuously till the consistency of the content changed to form a gel.

\section{Preparation of Specimens}

One hundred thirty-five extracted noncarious over-retained or physiologically mobile deciduous molars were stored in $0.01 \%$ thymol media until the commencement of the study. The specimens were washed with distilled water and dried with an absorbent paper. They were decoronated from the cementoenamel junction (CEJ) portion of the teeth, while root portions were discarded. The ideal class I cavity was prepared on all the specimens with the help of a round end, high-speed carbide bur nos. 330 and 245. Vertical grooves were made on buccal and lingual surface starting from the occlusal to the cervical region. All the prepared specimens were sterilized by a steam autoclave at $121^{\circ} \mathrm{C}$ for 15 minutes and the outer surface of the specimen was covered with two coats of impermeable dental varnish in a laminar chamber.

\section{Culturing Procedure}

The specimens were sterilized by ultraviolet radiation with a dosage $300 \mathrm{~kJ} / \mathrm{cm}^{2}$ for 10 minutes in the laminar air flow. The pure strain of S. mutans (MTCC 497) was grown in an overnight culture of brain heart infusion $(\mathrm{BHI})$ in a $10 \%$ carbon dioxide $\left(\mathrm{CO}_{2}\right)$ atmosphere. The class I cavity of each specimen was exposed to $20 \mu \mathrm{L}$ aliquot of $S$. mutans (MTCC 497) without any disturbance, to allow for bacterial adherence to the tooth surface. After 2 hours at the room temperature, the nonadhering cells were removed by washing with distilled water and were placed in Petri dishes for a while. Then, the specimens were transferred to the wells of a cell culture plate containing $2 \mathrm{~mL}$ of broth supplemented with $1 \%(\mathrm{w} / \mathrm{v})$ sucrose to simulate bacterial colonization. The plates were incubated for 18 hours at $37^{\circ} \mathrm{C}$ in a $5 \% \mathrm{CO}_{2}$ environment.

\section{Preparation of Specimens for Confocal Laser Scanning Microscope and Evaluation}

Liquorice/propolis gel was applied with a micropipette $(50 \mu \mathrm{L})$ and agitated on the entire dentin surface with a sterile applicator 
microbrush for 60,120 , and 180 seconds, and rinsed for 60 seconds with distilled water for each group (except control group III(i-iii)). Excess of all solutions was removed with an absorbent paper. As the deep grooves were already prepared on the buccal and lingual surfaces, so the application of mechanical pressure through a chisel facilitated splitting of the sample into two desired halves without disturbing the microbial colonization.

For observation under CLSM (ZIESS LSM 780 META GmbH, Mannheim, Germany), the stock solution of dyes was prepared as per manufactures instructions. We prepared the fluorescein diacetate (FDA) stock solution by dissolving $5 \mathrm{mg}$ of FDA in $1 \mathrm{~mL}$ acetone (storage temperature of FDA stock solution at $-20^{\circ} \mathrm{C}$ ). The propidium iodide $(\mathrm{PI})$ stock solution was prepared by dissolving $2 \mathrm{mg}$ of $\mathrm{PI}$ in $1 \mathrm{~mL}$ phosphate-buffered saline (PBS) (storage temperature of $\mathrm{PI}$ stock solution at $4^{\circ} \mathrm{C}$ ).

After coding the teeth samples, the teeth were stained with $50 \mu \mathrm{L}$ of stock solution of fluorescent dyes to observe under CLSM (ZEISS LSM 780 META GmbH, Mannheim, Germany) at 20x magnification. The excitation/emission wavelength for FDA is $488 / 561 \mathrm{~nm}$ and $561 / 634 \mathrm{~nm}$ for PI. The teeth were stained with $50 \mu \mathrm{L} F D A$ and $50 \mu \mathrm{L}$ of PI.

Scans were taken in 8 bits at a resolution of 512 by 512 pixels. The fluorescent images were analyzed by using the Java-based image analysis program ImageJ (1.50i, National Institute of Health, USA. Java 1.8.0_77, 64 bit) freeware, http://rsb.info.nih.gov/ij/) (Fig. 1). Fluorescence intensity profiles along the $x y$-axis of the original image stacks were determined for both the viable (green) and the nonviable (red) fluorescence channels. The initial stacks, comprising both green and red fluorescence, were split into individual component color channels and saved as a grayscale image with the help of ImageJ plug in ITCN. The red and green channels of the image were analyzed and their ratio (nonviable-red to viable-green) was calculated. A high ratio indicates a high antibacterial property of the cavity cleaning agent. The penetration was measured in $\mu \mathrm{m}$, with the help of the depth penetration tool from the ImageJ software.

\section{Statistical Analysis}

Statistical analysis was done using Statistical Package of Social Science (SPSS Version 20; Chicago Inc., USA). Statistical tests employed for the obtained data in our study were an analysis of variance (ANOVA), general linear model: repeated measure of ANOVA to compare mean value between different time intervals and Tukey's post hoc analysis for intragroup comparison. The significance level was fixed at $p<0.05$.

\section{Results}

In the present study, 135 extracted deciduous molars were randomly divided into three groups; group I $(n=45)$ which was treated with liquorice extract containing gel, group II $(n=45)$ with propolis extract containing gel, and group III $(n=45)$ was treated with distilled water (control). These three groups were further subdivided into three subgroups based on the duration of application of the cavity cleaning agent used for each group, i.e., 60,120 , and 180 seconds.

The mean ratio of nonviable bacterial count and bacterial depth of penetration was found to be maximum in group I (liquorice), followed by group II (propolis), and minimum in group III (controls) at all time intervals, i.e., 60, 120, and 180 seconds. There was a statistically high significant difference between liquorice and propolis extract gel at all time intervals $(p=0.001)$ (Tables 1 and 2 ).
When an intragroup comparison of non-viable/viable bacterial count in liqourice group was done at 60, 120, and 180 seconds, it showed a gradual increase in nonviable bacterial count from 60 seconds $(1.850 \pm 1.01)$, to 120 seconds $(2.157 \pm 0.93)$, and 180 seconds ( $2.194 \pm 1.31)$, but there was no statistically significant change ( $p=$ 0.669). Similarly, in group II (propolis), the nonviable count increased from minimum at 60 seconds $(0.939 \pm 0.062)$, to 120 seconds $(1.335 \pm$ $0.47)$ and 180 seconds $(1.353 \pm 0.31)$ which is statistically significant $(p=0.013)$. In the control group, no significant changes were seen at all the time intervals $(p=0.123)$ (Table 3$)$.

When an intragroup comparison of non-viable/viable bacterial depth of penetration in propolis group was done at 60, 120, and 180 seconds, it showed a gradual increase in nonviable bacterial depth from 60 seconds $(0.676 \pm 0.11)$, to 120 seconds $(0.708 \pm 0.068)$ and 180 seconds $(0.708 \pm 0.068)$, but there was no statistically significant change ( $p=0.576$ ). Similarly, in group II, it increased from minimum at 60 seconds $(0.382 \pm 0.053)$, to 120 seconds $(0.584 \pm 0.047)$ and 180 seconds $(0.690 \pm 0.058)$ which is a statistically significant $(p=0.001)$. In the control group, statistically no significant changes were seen at all the time intervals ( $p=0.421)$ (Table 3 ).

The intergroup comparison for nonviable and viable bacterial count between groups I and II was done, highly significant differences were seen at 60 seconds $(p=0.001)$ and 120 seconds $(p=0.002)$, whereas significant results were obtained at 180 seconds $(p=0.014)$. When the intergroup comparison for nonviable and viable bacterial count between groups I and III was done, a highly significant difference was seen at all the time intervals, i.e., 60, 120 , and 180 seconds $(p=0.001)$. But when groups II and III were compared, there was no statistically significant difference at all time intervals, i.e., 60,120 , and 180 seconds ( $p>0.05$ ).

The intergroup comparison for the ratio of nonviable and viable bacterial depth penetration between groups I and II was done, it showed that there was a highly significant difference at 60 seconds and 120 seconds $(p=0.001)$, while there was a statistically no significant difference 180 seconds $(p=0.701)$. When the intergroup comparison for nonviable and viable bacterial depth penetration between groups I and III and also for groups II and III, there was a highly significant difference at all the time intervals, i.e., 60, 120, and 180 seconds ( $p=0.001$ ) (Table 4$)$.

\section{Discussion}

Literature has reported that complete elimination of microorganisms after cavity preparation is not possible. It is well known that $S$. mutans are the principle colonizers capable of producing dental caries in humans. Moreover, González-Cabezas et al. concluded that S. mutans could be involved in the etiology of secondary caries. ${ }^{10}$ Bergenholtz et al. have also isolated Streptococci species from different types of failed restorations. ${ }^{11}$ Kidd et al. reported that mechanical cavity preparation does not eradicate all microorganism and, even in conventional restorative techniques, secondary caries leads to failure of restoration. ${ }^{12}$ The use of an antimicrobial disinfectant after cavity preparation to clean the cavity and, thus, enabling to reduce the bacterial count to minimal, is of importance, so as, to increase the success rate of restorations/treatment.

Various chemical cavity disinfectants have been used, of which, chlorhexidine is considered as "gold standard." But it comes with some drawbacks such as discoloration, increased chances of microleakage, reduction in shear bond strength of resin composite materials, and increased gingival gap., ${ }^{713-17}$ Moreover, the constant increase in antibiotic-resistant strains and the side effects caused by 


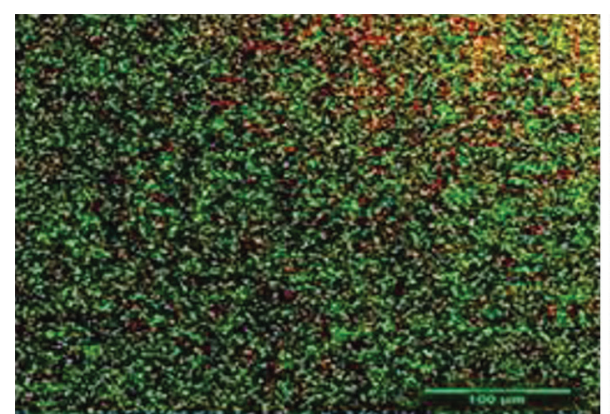

Group I (liquorice) at $60 \mathrm{sec}$

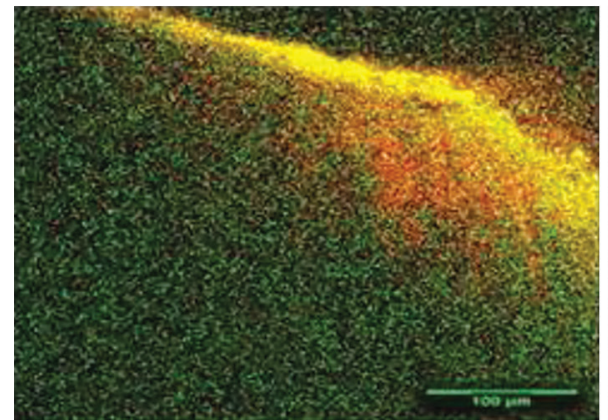

Group II (propolis) at $60 \mathrm{sec}$.

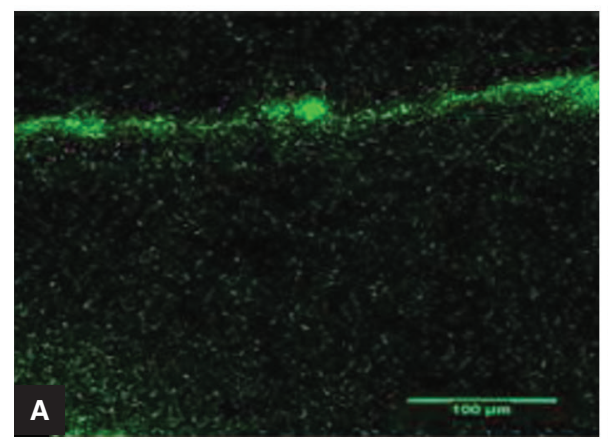

Group III (control) at $60 \mathrm{sec}$.

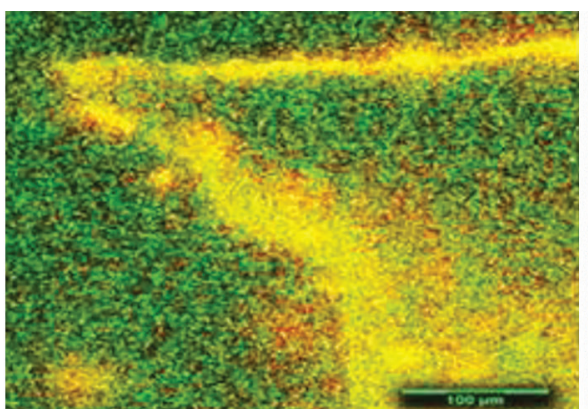

Group I (liquorice) at $120 \mathrm{sec}$.

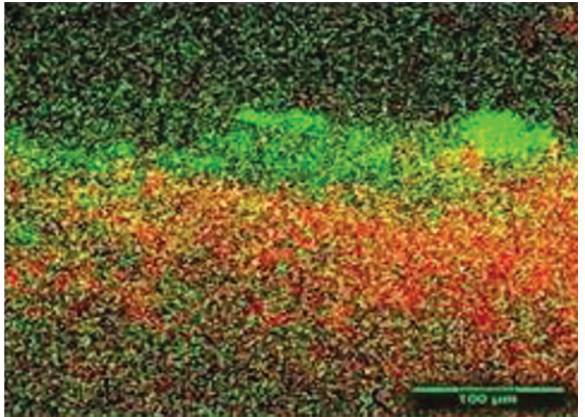

Group II (propolis) at $120 \mathrm{sec}$.

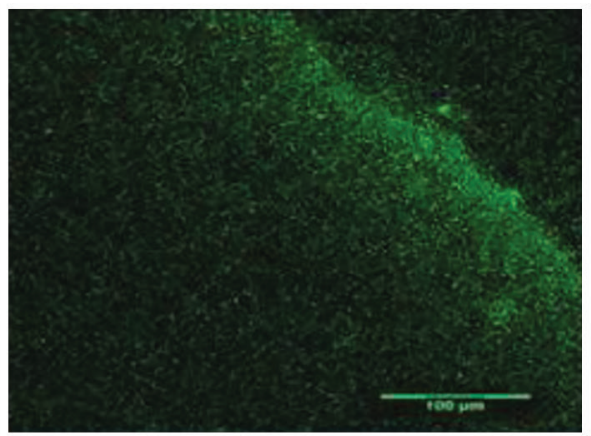

Group III (control) at $120 \mathrm{sec}$.

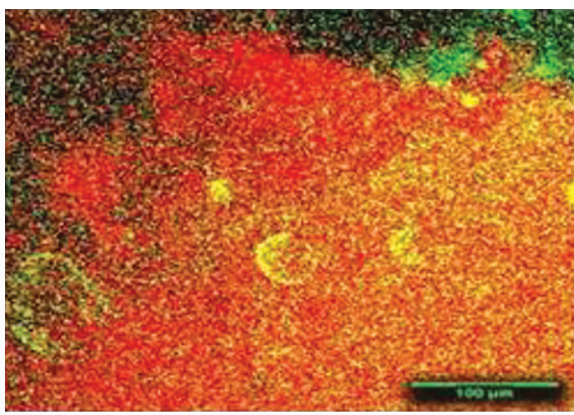

Group I (liquorice) at $180 \mathrm{sec}$.

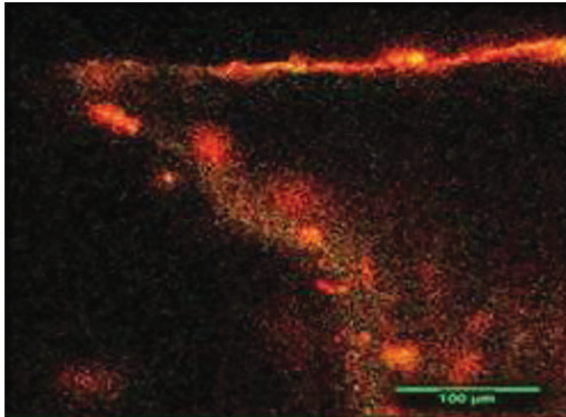

Group II (propolis) at $180 \mathrm{sec}$.

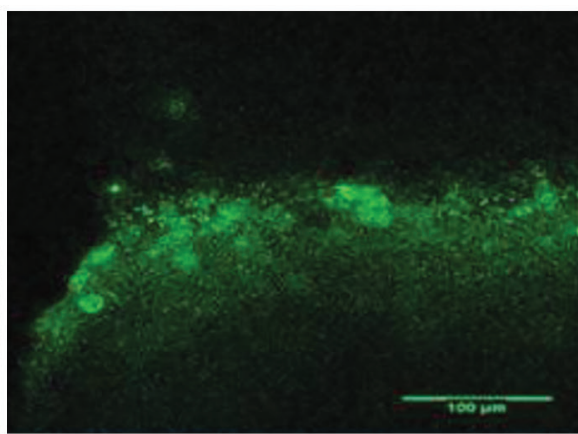

Group III (control) at $180 \mathrm{sec}$

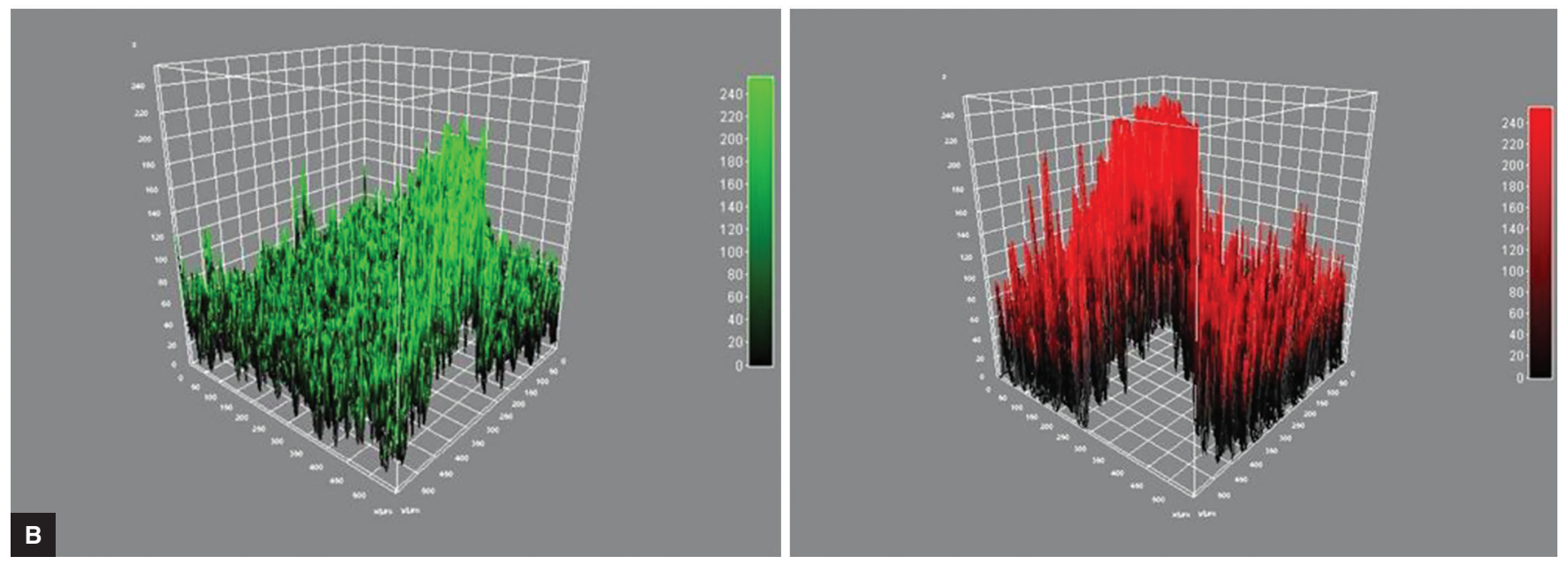

Figs 1A and B: (A) CLSM images (20X) for groups I to III at 60,120 , and 180 seconds, respectively; (B) Viable and nonviable fluorescence profile for penetration depth of viable bacteria (green) and penetration of nonviable bacteria (red)

synthetic drugs have prompted the need to search for safer herbal alternatives for achieving effective eradication could be beneficial.

In the present study, gels of liquorice and propolis extracts were used as cavity cleaning agents. Herbal extracts are an attractive proposition for many reasons like biocompatibility, minimal side effects, a wide margin of safety, and low chance of developing resistance in the microorganism. ${ }^{18}$ In the present study, the penetration and antibacterial properties of these phytochemicals 
Table 1: Comparison of mean nonviable/viable bacterial count ratio among liquorice and propolis extract gel at 60, 120, and 180 seconds

\begin{tabular}{llll}
\hline & \multicolumn{3}{l}{ Nonviable/viable bacterial count ratio } \\
\cline { 2 - 4 } Groups & 60 seconds & 120 seconds & 180 seconds \\
\cline { 2 - 4 } & Mean $\pm S D$ & Mean $\pm S D$ & Mean $\pm S D$ \\
\hline I. Liquorice & $1.850 \pm 1.01$ & $2.157 \pm 0.93$ & $2.194 \pm 1.31$ \\
II. Propolis & $0.939 \pm 0.062$ & $1.335 \pm 0.47$ & $1.353 \pm 0.31$ \\
III. Controls & $0.912 \pm 0.074$ & $0.914 \pm 0.072$ & $0.946 \pm 0.048$ \\
Total & $1.234 \pm 0.719$ & $1.468 \pm 0.78$ & $1.498 \pm 0.924$ \\
ANOVA & 12.634 & 16.422 & 10.038 \\
" $F$ "value & & & \\
" $p$ "value & $0.001(\mathrm{HS})$ & $0.001(\mathrm{HS})$ & $0.001(\mathrm{HS})$ \\
\hline
\end{tabular}

Table 2: Comparison of mean nonviable/viable bacterial ratio of depth of penetration among liquorice and propolis extract gel at 60, 120, and 180 seconds

\begin{tabular}{llll}
\hline & \multicolumn{3}{l}{ Nonviable/viable bacterial depth of penetration } \\
\cline { 2 - 4 } Groups & 60 seconds & 120 seconds & 180 seconds \\
\cline { 2 - 4 } \pm Mean $\pm S D$ & Mean $\pm S D$ & Mean $\pm S D$ \\
\hline I. Liquorice & $0.676 \pm 0.11$ & $0.694 \pm 0.070$ & $0.708 \pm 0.068$ \\
II. Propolis & $0.382 \pm 0.053$ & $0.584 \pm 0.047$ & $0.690 \pm 0.058$ \\
III. Controls & $0.254 \pm 0.059$ & $0.258 \pm 0.044$ & $0.265 \pm 0.046$ \\
Total & $0.437 \pm 0.19$ & $0.506 \pm 0.202$ & $0.554 \pm 0.214$ \\
ANOVA & 110.108 & 271.430 & 272.541 \\
" $F$ " value & & & \\
" $p$ " value & $0.001(\mathrm{HS})$ & $0.001(\mathrm{HS})$ & $0.001(\mathrm{HS})$ \\
\hline
\end{tabular}

were evaluated against S. mutans through CLSM. The extracts were prepared using the Soxhlet apparatus. The advantage of this system is that instead of numerous portions of warm solvent being passed through the sample, just a single batch of solvent is recycled..$^{19}$ Jain et al. ${ }^{20}$ affirmed that both aqueous and ethanolic liquorice extracts are potent cariostatic agents and are found to be palatable by child patients. A similar in vitro study was performed by Ajagannanavar et al. $^{21}$ to evaluate the effect of aqueous and alcoholic licorice (Glycyrrhiza glabra) root extract against S. mutans and Lactobacillus acidophilus in comparison to chlorhexidine and concluded that the inhibitory effect shown by alcoholic liquorice root extract against S. mutans and L. acidophilus was superior when compared with that of aqueous form and chlorhexidine. Hence, in our study, we prepared ethanolic extracts of liquorice and propolis which were then formulated into gels after establishing the minimum inhibition count for each.

In the present study, the specimens were sterilized using a steam autoclave, as this technique is simple and assures microbial death both externally and pulpally without affecting the physical properties of teeth as observed by Pantera and Schuster. ${ }^{22}$ Specimens were incubated for 18 hours which is sufficient to develop bacterial biofilm without producing an intense demineralization of dentin, because the demineralization process could increase the autofluorescence and harm the visualization by CLSM, this was in accordence with the previous studies done by Carvalho et al.9,23 The time for application of cavity cleaning agents was considered at 60,120 , and 180 seconds for each group. ${ }^{9}$

In the present study, the penetration of viable S. mutans bacteria in dentinal tubules was found to be up to 95.9, 92.1, and $92.7 \mu \mathrm{m}$ in group I; 116.3, 93.1, and $84.2 \mu \mathrm{m}$ in group II; and 128.9, 138.7, and $131.8 \mu \mathrm{m}$ in group III at 60,120 , and 180 seconds, respectively.

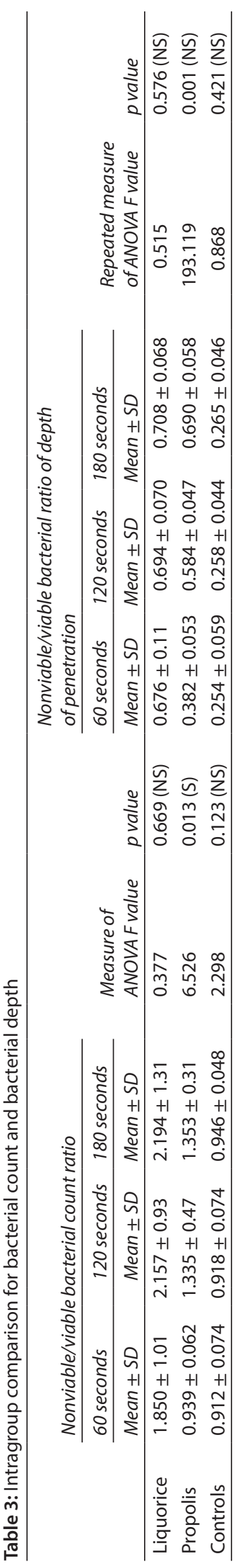


Table 4: Intergroup comparison for bacterial count and bacterial depth

\begin{tabular}{|c|c|c|c|c|c|c|}
\hline \multirow[b]{2}{*}{ Groups } & \multicolumn{3}{|c|}{ Bacterial count } & \multicolumn{3}{|c|}{ Bacterial depth } \\
\hline & 60 seconds & 120 seconds & 180 seconds & 60 seconds & 120 seconds & 180 seconds \\
\hline Group I vs group II & $0.001(\mathrm{HS})$ & $0.002(\mathrm{HS})$ & $0.014(\mathrm{~S})$ & $0.001(\mathrm{HS})$ & $0.001(\mathrm{HS})$ & 0.701 (NS) \\
\hline Group I vs group III & $0.001(\mathrm{HS})$ & $0.001(\mathrm{HS})$ & 0.001 (HS) & $0.001(\mathrm{HS})$ & $0.001(\mathrm{HS})$ & $0.001(\mathrm{HS})$ \\
\hline Group II vs group III & 0.991 (NS) & 0.147 (NS) & 0.333 (NS) & $0.001(\mathrm{HS})$ & $0.001(\mathrm{HS})$ & $0.001(\mathrm{HS})$ \\
\hline
\end{tabular}

Whereas Agematsu et al. ${ }^{24}$ reported that the oral bacteria can invade up to $250 \mu \mathrm{m}$ from the open end in deciduous anterior teeth, while Sen et al. ${ }^{25}$ observed through scanning electron microscope (SEM), the depth of bacterial penetration into dentinal tubules of root canal ranged from 10 to $150 \mu \mathrm{m}$. This variation may be due to different study designs, and preparation of samples, as for SEM, dehydrated samples were used, whereas in our study, no dehydration of samples was done since laser scanning confocal microscopy (LSCM) allows the evaluation of samples without the need for dehydration and, thus, the true native morphology of teeth was preserved. ${ }^{26}$

The penetration of different cavity cleaning agents applied for different time durations was assessed by the presence of nonviable bacteria inside the dentinal tubules.

The penetration of $S$. mutans was the highest in liquorice, i.e., $64.3,64$, and $65.8 \mu \mathrm{m}$ in group I; 44.4, 54.7, and $58.4 \mu \mathrm{m}$ in group II (propolis); and 32.5, 34.5, and $35.1 \mu \mathrm{m}$ in group III (control) at 60, 120 , and 180 seconds, respectively.

All cavity cleaning agents showed significant higher penetration than the control group (distilled water). The highest penetration was shown by liquorice followed by propolis extracts. The CLSM used in the present study differentiated viable and nonviable bacteria. ${ }^{9}$

CLSM has been utilized to check the antibacterial property of all subgroups based on nonviable and viable bacterial cell count. The highest nonviable bacterial count was observed in liquorice at 120 and 180 seconds, i.e., $2.157 \pm 0.93$ and $2.194 \pm 1.31$, respectively. In our study, liquorice extract has shown the highest antimicrobial activity against $S$. mutans at 60,120 , and 180 seconds which is in concurrent with Soderling et al. who studied the antibacterial activity of liquorice on different strains of $S$. mutans and concluded that liquorice showed good antimicrobial activity in both adherence and anti-bacterial assays. ${ }^{27}$

We found propolis extract showing high antimicrobial activity at 120 and 180 seconds as compared to at 60 seconds. Mohan et al. did an in vivo comparison of cavity disinfection efficacy with acidulated phosphate fluoride (APF) gel, propolis, diode laser, and $2 \%$ chlorhexidine in primary teeth and concluded that diode laser and Brazilian propolis are equally effective as $2 \%$ chlorhexidine $(\mathrm{CHX})$ in cavity disinfection and illustrated the need for cavity disinfection. ${ }^{28}$

Ghabanchi et al. ${ }^{29,30}$ found in their study that propolis (Apis mellifera) had only bacteriostatic activity, while Morawiec et al. ${ }^{31}$ stated that propolis showed good antimicrobial activity. This difference may be because of the variations in the composition of propolis.

But both the extracts showed positive antimicrobial activity for all the subgroups. Hence, both the extracts can be effectively used as alternative herbal agents for cavity disinfection.

However, till now, no study has been done with CLSM to compare the penetration and antibacterial property of both extracts. Hence, it is necessary to carry out a long-term study on a large sample to validate the efficiency of these herbal extracts.

\section{Conclusion}

- Liquorice extract has shownthe highest antimicrobial activity against $S$. mutans at 60,120 , and 180 seconds.

- Whereas, propolis extract has shown high antimicrobial activity at 120 and 180 seconds as compared to at 60 seconds.

- Penetration of non-viable cells was more in all the groups treated by liquorice extract as compared to propolis.

- Liquorice extract showed a better antimicrobial potential as compared to propolis extract. But, both liquorice extract and propolis extract have shown a positive antimicrobial activity against $S$. mutans. Hence, both can be used as potential cavity cleaning agents.

\section{ACKnOWLedgement}

The authors wish to acknowledge the Institutional Ethical Committee of People's College of Dental Science and Research Centre, Bhopal, Dr Arun Sharma, Dr Shilpy Singla, Dr Nikita Agrawal, Dr Shilpi Tiwari, Dr Shikha Mali, Dr Saurabh Kale, and Department of Paedodontics and Preventive Dentistry, People's College of Dental Science and Research Centre, Bhopal, Indian Institute of Science Education and Research, Bhopal, Lienence Microbiology Lab, Bhopal.

\section{References}

1. Borges FMC, Melo MAS, et al. Antimicrobial effect of chlorhexidine digluconate in dentin: in vitro and in situ study. J Conserv Dent Jan-Mar 2012;15(1):22-26. DOI: 10.4103/0972-0707.92601.

2. Neelakantan $P$, Jagannathan $N$, et al. Ethnopharmacological approach in endodontic treatment: a focused review. Int J Drug Dev Res 2011;3(4):68-77.

3. Malhotra S, Gupta VK. Use of propolis in pediatric dentistry. J Dent Sci 2014;3(2):93-98.

4. Sinha DJ, Sinha AA. Natural medicaments in dentistry. Ayu 2014;35(2):113-118. DOI: 10.4103/0974-8520.146198.

5. Koo H, Rosalen PL, et al. Effects of compounds found in propolis on Streptococcus mutans growth and on glucosyltransferase activity. Antimicrob Agents Chemother 2002;46(5):1302-1309. DOI: 10.1128/ aac.46.5.1302-1309.2002.

6. Bagade VB, Jadhav VM, et al. Study on antimicrobial activity of herbal formulation. Int J Pharma Life Sci 2013;4(11):3099-3104.

7. Hegde V, Kesaria DP. Comparative evaluation of antimicrobial activity of neem, propolis, turmeric, liquorice and sodium hypochlorite as root canal irrigants against $E$. faecalis and C. albicans-an in vitro study. Endod 2013;25(2):38-45.

8. Jeon JG, Rosalen PL, et al. Natural products in caries research: current (limited) knowledge, challenges and future perspective. Caries Res 2011;45:243-263. DOI: 10.1159/000327250.

9. Carvalho FG, Rontani RMP, et al. Analysis by confocal laser scanning microscopy of the MDPB bactericidal effect on S. mutans biofilm CLSM analysis of MDPB bactericidal effect on biofilm. J Appl Oral Sci 2012;20(5):568-575. DOI: 10.1590/s1678-77572012000500013.

10. Gonzalez-Cabezas C, Li Y, et al. Detection of mutans streptococci in secondary carious lesions using immunofluorescent techniques and 
confocal laser scanning microscopy. Caries Res 1995;29(3):198-203. DOI: 10.1159/000262069.

11. Bergenholtz G, Cox CF, et al. Bacterial leakage around dental restorations: its effect on the dental pulp. J Oral Pathol 1982;11(6): 439-450.

12. Kidd EA, Joyston-Bechal S, et al. Microbiological validation of assessments of caries activity during cavity preparation. Caries Res 1993;27(5):402-408. DOI: 10.1159/000261571.

13. Borges FMC, Melo MAS, et al. Antimicrobial effect of chlorhexidine digluconate in dentin: in vitro and in situ study. J Conserv Dent JanMar 2012;15(1):22-26. DOI: 10.4103/0972-0707.92601.

14. Pattanaik N, Chandak M. Topic-the effect of three cavity disinfectants (chlorhexidine gluconate-based. Consepsis; benzalkonium chloritebased, Tubulicid red; sodium hypochlorite based-Chlorcid $V$ on the self-etch dentine bonding agent (Adeper Easy One, 3M ESPE) under SEM. J Dent Med Sci 2013;8(5):84-89.

15. Singla $M$, Aggarwal $V$, et al. Effect of chlorhexidine cavity disinfection on microleakage in cavities restored with composite using a selfetching single bottle adhesive. J Conserv Dent 2011;14(4):374-377. DOI: $10.4103 / 0972-0707.87201$.

16. Hassan AM, Goda AA, et al. The effect of different disinfecting agents on bond strength of resin composites. Int J Dent 2014;2014:231235. DOI: $10.1155 / 2014 / 231235$.

17. Kimyai S, Pournaghi-Azar F, et al. Effect of disinfecting the cavity with chlorhexidine on the marginal gaps of CIV giomer restorations. J Clin Exp Dent 2017;9(2):e202-e206. DOI: 10.4317/jced.53193.

18. Gandhi R, Gandhi S, et al. Sanjeevani- A New Hope in Dentistry. J Interdiscipl Dent Sci 2014;3(1):20-23.

19. Castro MDL, Gracia-Ayuso LE. Soxhlet extraction of solid materials: an outdated technique with a promising innovative future. Anal Chim Acta 1998;369(1):1-10.

20. Jain E, Pandey RK, et al. Liquorice root extracts as potent cariostatic agents in pediatric practice. J Indian Soc Pedod Prev Dent 2013;31(3):146-152. DOI: 10.4103/0970-4388.117964.

21. Ajagannanavar $\mathrm{SL}$, Battur $\mathrm{H}$, et al. Effect of aqueous and alcoholic licorice (Glycyrrhiza Glabra) root extract against Streptococcus mutans and Lactobacillus acidophilus in comparison to chlorhexidine: an in vitro study. J Int Oral Health 2014;6(4):29-34.

22. Pantera EA, Schuster GS. Sterilization of extracted human teeth. J Dent Educ 1990;54(5):283-285.

23. Carvalho FG, Fucio SBP, et al. Confocal laser scanning microscopic analysis of the depth of dentin caries-like lesions in primary and permanent teeth. Braz Dent J 2008;19(2):139-144.

24. Agematsu $\mathrm{H}, \mathrm{Abe} \mathrm{S}$, et al. Relationship between large tubules and dentin caries in human deciduous tooth. Bull Tokyo Dent Coll 2005;46(1-2):7-15.

25. Sen $\mathrm{BH}$, Piskin B, et al. Observation of bacteria and fungi in infected root canals and dentinal tubules by SEM. Endod Dent Traumatol 1995;11(1):6-9.

26. Paterson SM, Casadio YS, et al. Laser scanning confocal microscopy vs scanning electron microscopy for characterization of polymer morphology: sample preparation drastically distorts morphologies of poly(2-hydroxyethyl methacrylate)-based hydrogels. J Appl Polym Sci 2013;127(6):4296-4230.

27. Soderling $E$, Karjalainen $S$, et al. The effect of liquorice extract containing starch gel on the amount and microbial composition of plaque. Clin Oral Investig 2006;10:108-113. DOI: 10.1007/s00784-0060040-9.

28. Mohan PVMU, Uloopi KS, et al. In vivo comparison of cavity disinfection efficacy with APF gel, propolis, diode laser, and $2 \%$ chlorhexidine in primary teeth. Contemp Clin Dent 2016;7(1):45-50. DOI: 10.4103/0976-237X.177110.

29. Ghabanchi J, Bazagani A, et al. In vitro assessment of anti-Streptococcus mutans potential of honey. Iran Red Crescent Med J 2010;12(1): 61-64.

30. Mahabala KY, Shrikrishna SB, et al. Ethanolic extracts of Aloe vera and propolis as cavity disinfectants: an in vitro study. Dent Hyp 2016;7(2):61-66.

31. Morawiec T, Mertas A, et al. The assessment of oral microflora exposed to $3 \%$ ethanolic extract of Brazilian green propolis preparation used for hygiene maintenance following minor oral surgeries. Biomed Res Int 2015;2015:869575. DOI: 10.1155/2015/869575. 